\title{
Using Virtual Reality in K-12 Education: A Simulation of Shooting Bottle Rockets for Distance
}

\author{
http://dx.doi.org/10.3991/ijep.v2i4.2215 \\ C.R. Nippert \\ Widener University, Chester, PA, USA
}

\begin{abstract}
Two liter bottle rockets made from recycled soda bottles are often used in high school science classes and in introductory college courses. Typically, it is often more challenging to shoot bottle rockets for distance instead of shooting them straight up and measuring altitude, as is often done. Using a device made from pipe and wood to launch bottle rockets and control the launch angle creates a m+uch0 more interesting problem for students who are attempting to optimize launch conditions. Plans are presented for a launcher that allow students to adjust the launch angle. To help embellish the exercise, we supplement the bottle rocket with a model using virtual reality and a photorealistic simulation of the launch that allows the students to appreciate the optimization problems associated with water and air pressure and launch angle. Our usage data indicates that students easily adapt to the virtual reality simulation and use our simulation for intuitive experiments on their own to optimize launch conditions.
\end{abstract}

Index Terms-Physics education, student experiments, courseware, computer aided instruction

\section{INTRODUCTION}

The $2 \mathrm{~L}$ bottle rocket, made from a recycled soda bottle, containing water and air under pressure is a staple in high school and introductory science and engineering classes. Many websites describe how bottle rockets are constructed and launched and some websites provide simulations to estimate altitude if the rocket is launched straight up. Frequently, students construct bottle rockets, launch them and attempt to estimate the bottle's maximum height using triangulation. A variation that we have used involves launching the rocket to achieve maximum distance using a launcher that allows students to adjust the launch angle and shoot their rocket. This complicates the challenge of designing a bottle rocket and creates a several challenging problems for students to solve; finding the launch angle and the maximum amount of water. Students often design wings to produce rotation and a more stable flight. A simple launcher shown in Figure 1, was developed and built. Students can easily set the launch angle and adjust their launch conditions.

Additionally, the author wrote an intuitive Virtual Reality simulation was created that students can use to prepare for their experiments. This simulation can also serve as a substitute for a launching device in inclement weather.

Use of the simulation occurs while students design their rockets using the simulation to optimize their operating conditions (for example, measuring the optimum amount

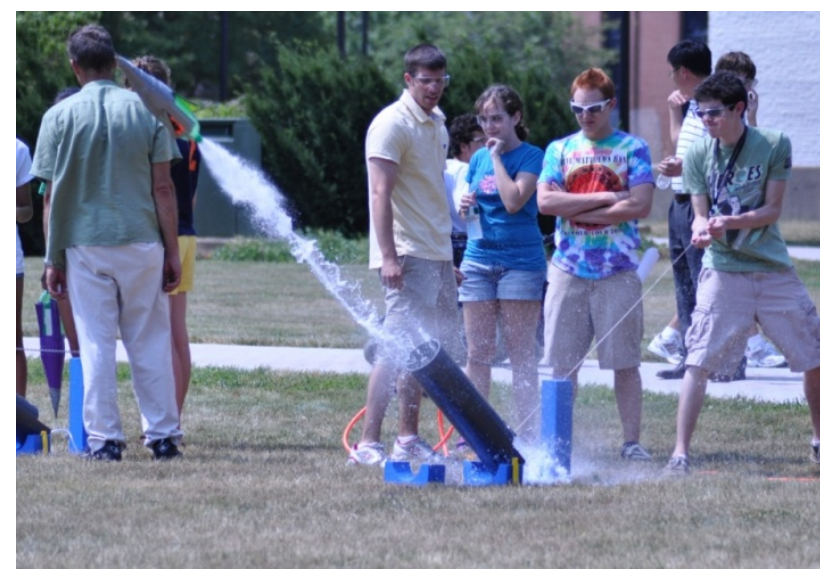

Figure 1. Bottle Rocket Launcher showing students adjusting angle

of water). The URL to the simulation given below works with Windows (http://www2.widener.edu/ crn0001/ Bottle/images/BottleEnt.htm) is provided with the simulation where students can run the virtual experiment. Normally, students are able to launch their rockets a field on our campus which is recreated virtually in the simulation/

\section{DESIGN OF A ROCKET LAUNCHER TO CONTROL LAUNCH ANGLE}

The launcher shown in Fig. 2 and 3 (below) consists of a 25 inch long, 6 inch diameter plastic pipe attached to a with a hinge to a wood base with a semicircular block that acts as a rest for the pipe. The rest is attached to $a 3 / 4$ inch plywood base. The pipe's angle can be adjusted by adjusting the chain attached to the "muzzle end" of the pipe and connected to a $2 \times 4$ at the end of the device. Adjusting the chain allows students to easily set the angle. Figures 3 and 4 show the clamp assembly that holds the bottle rocket, loaded with water and attached to a line connected to a portable air compressor that pressurizes the rocket until it is launched. A dimensional sketch the launcher is detailed in Figure 4. Fingers made from $1 / 4$ inch aluminum bar stock, grip the end of the bottle and are held in place by $1 / 8$ inch rod bent into a $u$ shape. Students launch the rocket by pulling a string attached to the rod.

\section{VIRTUAL EXPERIMENT}

The actual launcher was designed in the late 1990's and has served students, teachers and visitors very well for many years. Several of these launchers were built to accommodate the needs of the various constituencies. The bottle rocket experiments have become a staple of several 
recruiting efforts, a freshman lab etc, etc. Part of the fun for the students comes from the fact that there are now many more variables for them to adjust and optimize (launch angle, Ratio of water to air, payload). Ballistic flight is much more complicated than the problem of shooting vertically for height. To capture some of the fun of the actual experiment, the simulation using Java Open GL Figure 5 was written. The screen design (Figure 5) shows the various controls on the left side of the screen to simplify operation and a virtual world (showing the field of our campus (on the right).

The simulation of the bottle rocket was created to supplement the bottle rocket experiment. A Java ${ }^{\mathrm{TM}}$ applet using openGL was created using a virtual world that included the field in the middle of our campus. The screen was set up to maximize usability and make the operation of the simulation intuitive as possible. Students can adjust the launch angle by dragging the cursor over the launcher or adjusting the a slider in the panel on the left. Sliders are used for all the controls. Students can also "color" their rocket, which enhances the visibility of the launch, much as in the real world. Controls were placed on the left hand side of the screen where they were always visible. Making the variables readily visible and the simulation was easily usable. After launching the rocket, the path and altitude are shown below the title in the upper portion of the screen.

\section{A. The Simulation}

The model of the rocket was kept simple. No attempt was made to correct for changes in the center of gravity due to the change in water mass.

The forces acting on the bottle rocket are:

1. Gravity

2. Drag as the rocket moves through the air, computed from the equation which is

$$
F_{D}=C_{D} \rho A v^{2}
$$

$$
\begin{aligned}
& \text { Where } \quad \rho=\text { the } \begin{array}{c}
\text { density of air } \\
\text { the }
\end{array} \mathrm{F}_{\mathrm{D}}=\begin{array}{r}
\text { arag } \\
\text { force }
\end{array} \\
& \text {. } \mathrm{CD}=\text { the drag coefficient }
\end{aligned}
$$

3. The thrust from the water at the discharge of the bottle

The force of wind, often an important component in reality is neglected in this model as beyond the scope of a high school problem

The drag coefficient is related to the aspect ratio of the nose cone (ratio of diameter of the base to height). This relationship is specified for several aspect ratios (reference 1) and was fit to the equation

$$
C_{D}=\exp (-.54294 \ln (r)-0.26354)
$$

where $C_{D}=$ the drag coefficient

$$
\mathrm{r}=\text { the ratio of diameter to height }
$$

Thrust comes from water being forced out under pressure (as seen in figure 1). When the amount of water in the bottle reaches 0 or the pressure in the bottle reaches $1 \mathrm{~atm}$; the thrust stops. In practice, we observed anecdotally that when too much water is added to the bottle, some water may remains at the end of the flight
Two Liter Bottle Rocket Launcher

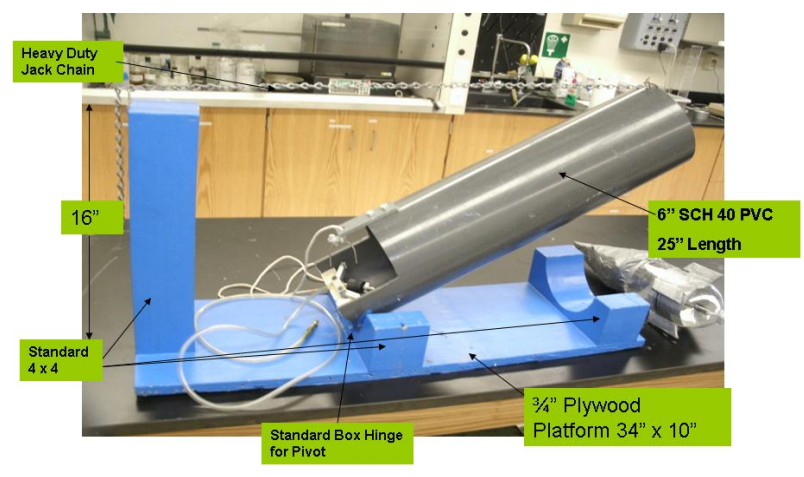

Figure 2. Bottle rocket launcher, detail

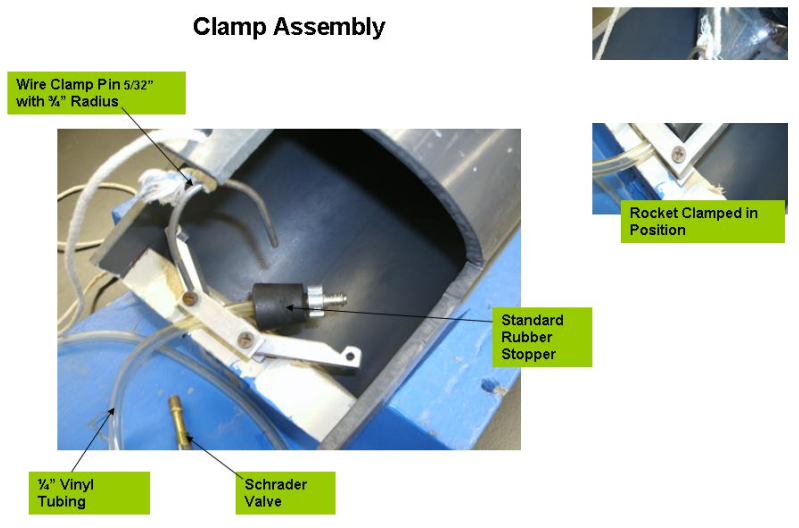

Figure 3. Clamp assembly
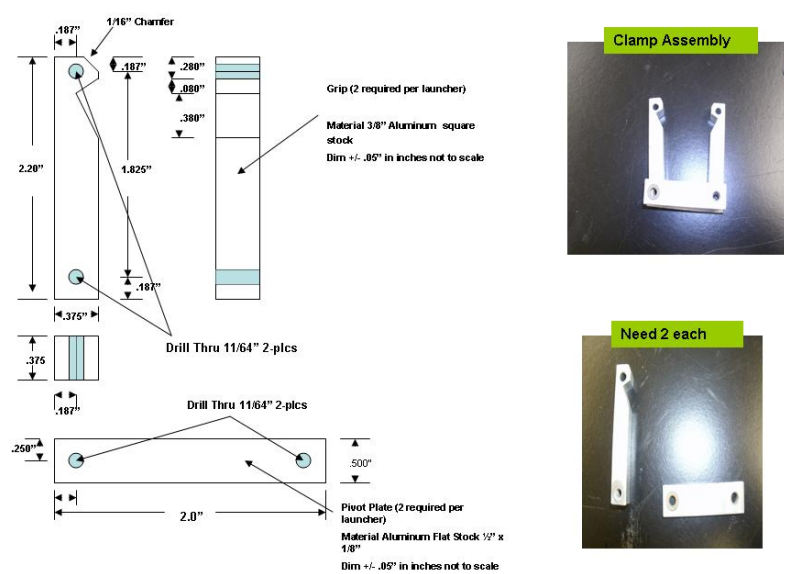

Figure 4. Clamp Assembly Detail

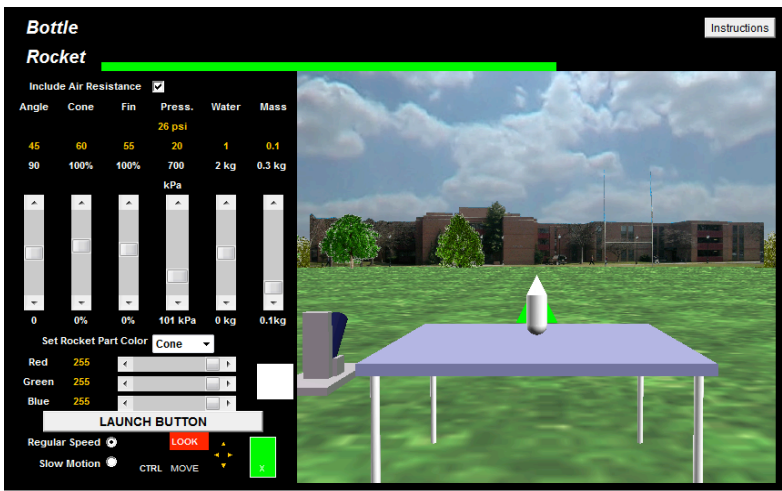

Figure 5. Screenshot of Bottle Rocket Simulation 
The model assumes that the compressed air is an ideal gas that expands adiabatically as water is expelled from the bottle (we noted that the bottles have cooled on landing). Thus the relationship between pressure and volume is

$$
P V^{k}=K
$$

Where $\mathrm{P}=$ air pressure

$\mathrm{V}=$ - the volume of the compressed air in the

bottle rocket

$\mathrm{k}=$ the ratio of heat capacities (1.41 for air)

$\mathrm{K}=\mathrm{a}$ constant for the process

$\mathrm{K}$ is calculated from volume of air initially present is the difference between the volume of the bottle and the volume of water added at launch and the gage pressure of the air supply. In the simulation, both variables are specified by sliders that are visible in the control panel to the left of the virtual world.

The velocity of the water at discharge relative to the bottle is calculated from Bernouilli's equation

$$
v^{2}=\frac{\Delta P}{\rho}
$$

where $\Delta \mathrm{P}=$ the pressure difference between the air in the bottle and the surroundings ( $1 \mathrm{~atm})$ $\mathrm{v}=$ the velocity of water at the discharge

The rate of loss of water is $\frac{d V}{d t}=-A v$

Where $\mathrm{A}=$ the cross sectional area of the $2 \mathrm{~L}$ bottle opening.

The water discharge continues until the volume of water in the bottle is 0 . When the mass of water in the rocket becomes 0 , power flight is ended. The additional thrust from any remaining compressed air is ignored.

The differential equations describing position (height and horizontal location) are solved using a Euler integration for an interval of $50 \mathrm{msec}$ to provide a smooth animation.

The result is a program that produces a smooth animation on most computers.

\section{ASSESSMENT OF THE SIMULATION}

Conventional assessment of student learning is not always consistent with the uses of this experiment; such as summer camps. Assessment of the usability of the simulation, however, is both possible and necessary. This allows monitoring the use and the conditions to determine how the students use the simulation. During a summer camp, the simulation shown in Figure 5 was used in conjunction with the students' preparation for actual launches of the bottle rocket using techniques similar to those that moni-

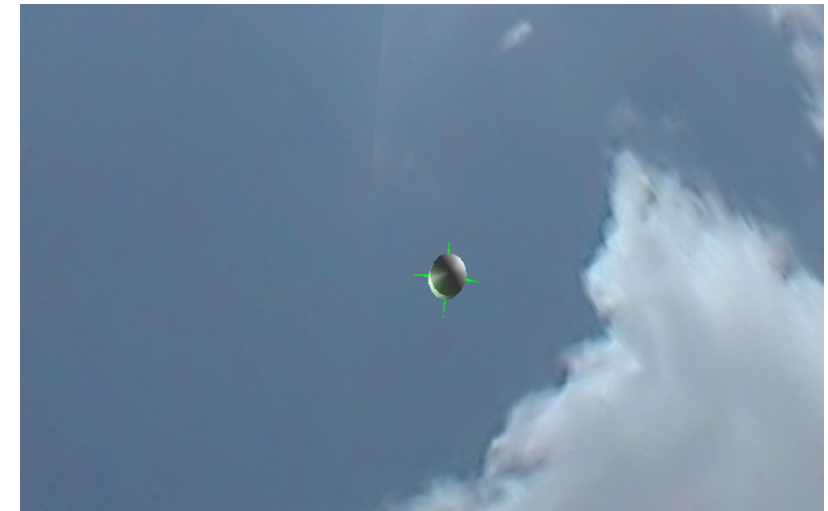

Figure 6. Standing underneath the rocket's landing point Don't try this at home, folks. We're what you call experts

tor usage on commercial websites. We found that participants in the summer camp ran the simulations for an average of 17 minutes, needing no instruction, or prompting beyond telling them the URL of the simulation. Students launched the bottle rocket an average of 31 times during this period. Although not asked to, $74 \%$ or nearly three quarters of the students ran a simulation in which the effects of air were removed. This indicates that the air drag button was visible and students were able, on their own, to determine that air drag might be a significant variable. Obviously, this experiment cannot be done in the real world. We could also determine that students used the simulation to optimize launch angle.

Finally, an interesting point in using the simulation is that (unlike the protype operation) students can "move" to anywhere in the field, including standing directly underneath where the rocket lands. This can produce an exciting experience that many students have attempted using the simulation.

\section{REFERENCE}

[1] “A Brief Intro to Fluid Mech, 2nd ed.", Donald Young, Bruce Munson, Theodore H. Okiishi, Wiley p. 393

\section{ACKNOWLEDGMENT}

The author wishes to acknowledge the following contributions of students and staff who assisted in developing the simulation.

Andrew Nodolski Chemical Engineering technician who aids in directing students during bottle rocket launches.

Richard DiCristino, a Widener student, took the pictures and helped develop the JAVA applet and its GUI

\section{AUTHOR}

C. R. Nippert holds the position of Associate Professor and Chair of the Department of Chemical Engineering at Widener University in Chester PA.

Submitted, July 23, 2012. Published as resubmitted by the author on October 05, 2012. 